\title{
CARACTERIZAÇÃO GEOTÉCNICA DE SOLOS DE ALTERAÇÃO DE ROCHAS ARENOSAS DO GRUPO ITARARÉ NA REGIÃO DE CAMPINAS - SP
}

\section{Daniel Luís Mantovani Marsura*, David de Carvalho.}

\section{Resumo}

O Grupo Itararé é um grupo de formações geológicas pertencentes à Bacia do Paraná. As rochas sedimentares atribuídas a esse Grupo também afloram na região de Campinas-SP, na qual amostras foram extraídas e caracterizadas.

\section{Palavras-chave:}

Itararé, solo residual, ensaios de laboratório.

\section{Introdução}

O Grupo Itararé é um grupo de formações geológicas pertencentes à Bacia do Paraná. As rochas sedimentares atribuídas ao Grupo Itararé afloram na borda leste da Bacia do Paraná nos estados de São Paulo, Paraná, Santa Catarina e Rio Grande do Sul. São constituídas por litotipos variados, desde lamitos até diamictitos ${ }^{1}$. Em Campinas-SP predominam os litotipos arenosos ${ }^{2}$, que apresentam normalmente perfis de solo com espessura de até 10-12 metros e predomínio de horizontes saprolíticos no perfil de alteração ${ }^{3}$.

Este projeto teve como objetivo contribuir para a caracterização geotécnica, através de ensaios laboratoriais em amostras deformadas e indeformadas, dos solos de alteração desenvolvidos a partir das rochas arenosas atribuídas ao Grupo Itararé em Campinas-SP.

\section{Resultados e Discussão}

Em um talude de exposição de solos de alteração de arenitos foram coletadas duas amostras (deformadas e indeformadas).

Em relação às amostras deformadas, o ensaio granulométrico seguiu a norma NBR 7181/84 da ABNT e foi realizado por uma combinação de peneiramento e sedimentação. Após o processo de peneiramento, uma pequena quantidade da amostra $(100 \mathrm{~g})$ seguiu para o processo de sedimentação. Várias leituras foram realizadas como a temperatura e a altura da queda.

Os limites de liquidez e de plasticidade seguiram as normas NBR 6459/84 e NBR 7180/84 da ABNT, respectivamente. O limite de liquidez é definido como a umidade abaixo da qual o solo se comporta como material plástico, ou seja, é a umidade de transição entre os estados líquido e plástico do solo. Já o limite de plasticidade é tido como o teor de umidade em que o solo deixa de ser plástico, tornando-se quebradiço, ou seja, é a umidade de transição entre os estados plástico e semisólido do solo. Esses ensaios foram realizados a partir de misturas homogeneizadas da amostra com água. Os limites encontrados foram: limite de liquidez (LL) $31,9 \%$ e limite de plasticidade (LP) 22,6\%. O índice de plasticidade (LL - LP) se baseou em 9,3\%.

Nas amostras indeformadas foram realizados os ensaio de compressão triaxial e o ensaio de cisalhamento direto que obteve 0 angulo de atrito $\left(30,1^{\circ}\right)$ e 0 valor da coesão $(8,2 \mathrm{kPa})$. Com esses valores, foi possível analisar a estabilidade de um talude de 7 metros de altura, utilizando o método de Fellenius, com peso específico de
$16,6 \mathrm{kN} / \mathrm{m} 3$, inclinação de 30 graus e sobrecarga de $20 \mathrm{kPa}$ (conforme a NBR 11.682-09/ABNT).

Figura 1. Solo do Grupo Itararé em Campinas-SP
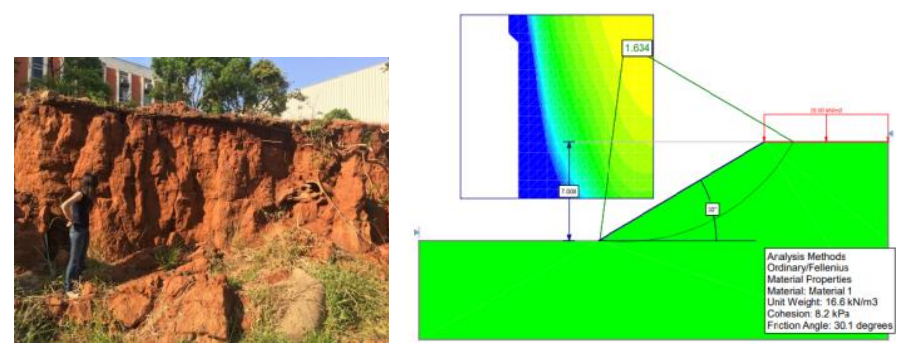

Figura 2. Estabilidade e fator de segurança do talude

\section{Conclusões}

Diante dos dados dos ensaios realizados, foi possível caracterizar o solo como franco arenoso e pouco plástico. Os ensaios de resistência permitiram a determinação da coesão e ângulo de atrito do solo. Estes parâmetros permitem a utilização de cálculos de capacidade de carga de fundações e estabilidade de taludes. A análise da estabilidade do talude em questão indica que o mesmo atende o coeficiente de segurança de 1,5 .

\section{Agradecimentos}

Agradecimentos ao apoio do SAE/AF-UNICAMP, FEAGRI e FEC.

1 Vesely, F.F. Dinâmica sedimentar e arquitetura estratigráfica do Grupo Itararé (Carbonífero-Permiano) no centro-leste da Bacia do Paraná. Tese de doutorado. Universidade Federal do Paraná: Curitiba. 226p, 2006.

${ }^{2}$ Basso, J.B. Migração de $\mathrm{K}+, \mathrm{Cu} 2+$ e $\mathrm{Cl}$ - em solos do subgrupo Itararé no estado de São Paulo: ensaios sorcivos, percolação em colunas e simulações geoquímicas. Universidade Estadual Paulista Júlio de Mesquita Filho: Rio Claro. 189p, 2010.

3 Ishikawa, A.K. Carta geológico-geotécnica aplicada ao planejamento urbano da região do córrego Bertini, município de Americana, SP. Trabalho de Conclusão de Curso. Universidade Estadual Paulista Julio de Mesquita Filho: Rio Claro. $55 \mathrm{p}, 2009$.

ABNT NBR 7181/84 Análise Granulométrica. Rio de Janeiro, 1984.

ABNT NBR 6459/84 Solo: determinação do limite de liquidez. Rio de Janeiro, 1984a. 6p

ABNT NBR 7180/84 Solo: determinação do limite de plasticidade. Rio de Janeiro, 1984b. 3p.

ABNT, NBR 11.682/09. Estabilidade de Encostas. Rio de Janeiro, 2009. 